\title{
Teachers and Counselors: Building Math Confidence in Schools
}

\author{
Joseph M. Furner ${ }^{1 *}$ \\ ${ }^{1}$ Ph.D., Florida Atlantic University, Jupiter, Florida, UNITED STATES \\ *Corresponding Author: jfurner@fau.edu \\ Citation: Furner, J.M. (2017). Teachers and Counselors: Building Math Confidence in Schools. European \\ Journal of STEM Education, 2(2), 3. https:/ / doi.org/10.20897/ ejsteme.201703
}

Published: August 30, 2017

\begin{abstract}
Mathematics teachers need to take on the role of counselors in addressing the math anxious in today's math classrooms. This paper looks at the impact math anxiety has on the future of young adults in our high-tech society. Teachers and professional school counselors are encouraged to work together to prevent and reduce math anxiety. It is important that all students feel confident in their ability to do mathematics in an age that relies so heavily on problem solving, technology, science, and mathematics. It really is a school's obligation to see that their students value and feel confident in their ability to do math, because ultimately a child's life: all decisions they will make and careers choices may be determined based on their disposition toward mathematics. This paper raises some interesting questions and provides some strategies (See Appendix A) for teachers and counselors for addressing the issue of math anxiety while discussing the importance of developing mathematically confident young people for a high-tech world of STEM.
\end{abstract}

Keywords: math anxiety, teaching, strategies, counselors, STEM

\section{THE TRUTH IS THAT MATH ANXIETY EXISTS: AN INTRODUCTION}

Today math teachers in the United States and many other countries around the world almost have to take on the role of counselors in their classrooms to address the many students who dislike or are fearful of mathematics. Mathematics teachers are encouraged to work with professional school counselors in helping to address the many math anxious students in today's schools. In an age of STEM (Science, Technology, Engineering, and Mathematics), it is critical that teachers today had better prepare all students to succeed with and be confident in their ability to do mathematics so to compete globally. It really has become a pandemic in our society where so many young people and adults have negative feelings and poor past experiences with mathematics instruction (Beilock \& Willingham, 2014; Boaler, 2008; Dowker, Sarkar, \& Looi, 2016; Geist, 2010). Some voices from young people in the USA about mathematics include the following:

\author{
“I really don't like math, but I do okay.”-Julie, 14 \\ "I just don't like math, it's the same thing and big numbers, and I don't like big numbers." - Brian, 13 \\ "I have lots of math anxiety, for me math is very confusing." - Samantha, 19 \\ "Frustration, sweaty palms, and fear are words I would use to describe what math does to me." - Heather, 34 \\ "When I hear the word math I get goosebumps." - Starry, 9
}




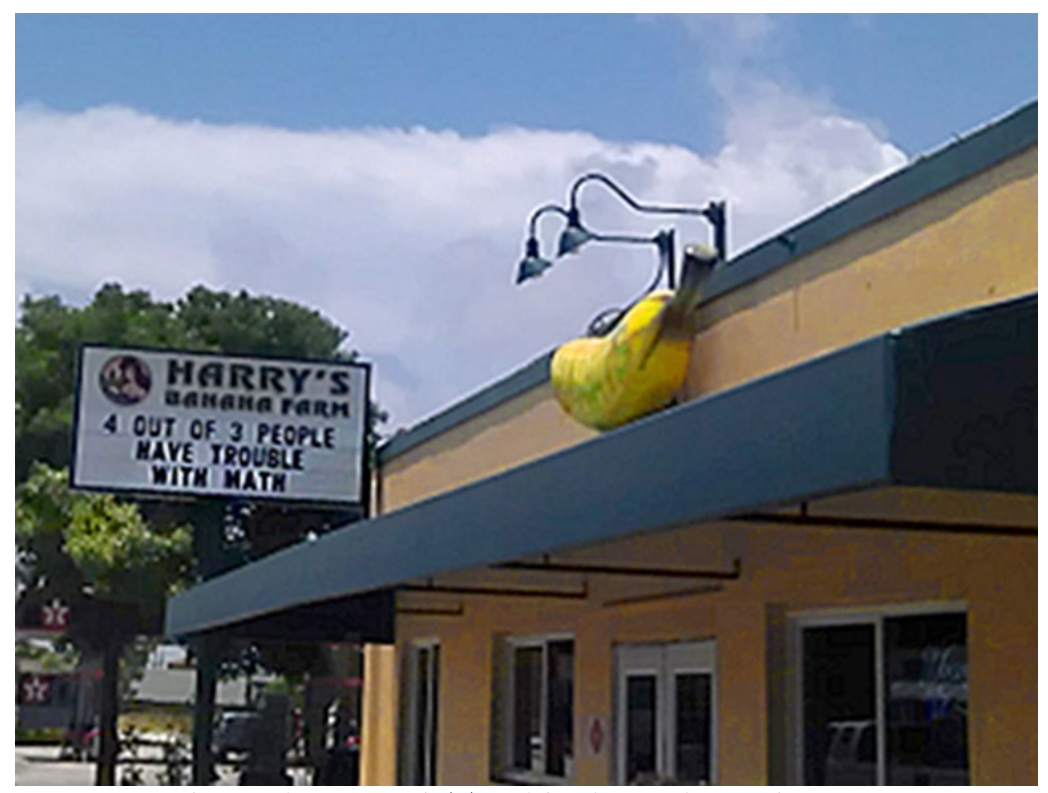

Figure 1. Photo about Math Troubles in Society, Photo-J. Furner

\author{
"Math makes me shake." - Seth, 10 \\ "When I think of math I don't get nervous I get bored." - Chad, 11
}

The statement on the marquis above (see Figure 1) and the comments from the young people above in regards to their feelings toward mathematics are just a sampling of how many children and adults feel about math today in the $21^{\text {st }}$ century. Anyone today can easily take an informal poll on the street and find that most respondents will not report positive experiences, feelings, and attitudes toward mathematics. However, we are now living in an age that depends so heavily on one being good at mathematics and problem solving. We are living in a world in which our students will soon be competing with young people from all parts of the globe for jobs (Neunzert, 2000). It is imperative that our students develop positive dispositions toward mathematics and the sciences in an information age of which has become so technologically oriented. Young people today need to be well prepared in the areas of math, science, and technology for all career choices specially now with the emphasis on STEM in our society. Nurses, engineers, architects, lawyers, teachers, along with many other fields will continue to use more advanced forms of technology that require one to know more mathematics and problem solving to perform their jobs more effectively. Sequencing, ordering, patterning, logic, spatial sense, and problem solving are some of the truly basic skills that all careers require (NCTM, 2000). A student's confidence and ability to do mathematics and apply these skills in many diverse settings is essential for success; therefore, our young people need to be well prepared to do the mathematics of the $21^{\text {st }}$ century.

According to Reuters (2007) and the American Association for the Advancement of Science in San Francisco, math anxiety saps working memory to do mathematics. Often times, worrying about doing math takes up a large part of a student's working memory, which then spells disaster for the anxious student who is taking high-stakes tests. Today math teachers from around the world almost have to take on the role of counselors in their classrooms to address the many students who dislike or are fearful of mathematics. Mathematics teachers are encouraged to work with school counselors in helping to address the many math anxious students in today's schools. It really has become a pandemic in our society where so many young people and adults have negative feelings and poor past experiences with mathematics instruction.

Ruff \& Boes (2014) found that low math achievement is a recurring weakness in many students. They see math anxiety as a persistent and significant theme to math avoidance and low achievement. Causes for math anxiety include social, cognitive, and academic factors. Interventions to reduce math anxiety are limited as they exclude the expert skills of professional school counselors to help overcome this nervousness often times. The effectiveness of a school counseling small group intervention to reduce math anxiety and increase achievement in fifth grade participants were some of the results of their research study. This study found that math teachers need to pair up with school counselors to address the math anxiety in their students. This paper also supports this approach to math instruction.

Steen (1999) points out "national and international studies show that most U.S. students leave high school with far below even minimum expectations for mathematical and quantitative literacy." Neunzert (2000) found in this research that today humans need to understand ourselves as MINT-professionals, where MINT is $\mathrm{M}=$ mathematics, $\mathrm{I}=$ informatics, $\mathrm{N}=$ natural sciences, $\mathrm{T}=$ =technology. Neunzert (2000) contends that mathematics 
is critical for people living in the $21^{\text {st }}$ Century for them to be successful. Neunzert concluded that teacher's ad our society as a whole need to encourage our students in all countries to study more mathematics and to see it as a tool for success in life.

Math anxiety remains a perplexing, persistent, and only partially understood problem from which many people suffer, National Council of Teacher of Mathematics (NCTM) (1991, p. 6) says, "Classrooms should be mathematics communities that thrive on conjecturing, inventing, and problem solving, and that build mathematical confidence. Unfortunately, in this day and age many young people and adults do not feel confident in their ability to do math.

Mathematics anxiety in students has become a concern for our high-tech world not just the USA (Brown, Brown, \& Bibby, 2008). Is it possible that only about 7 percent of Americans have positive experiences with mathematics from kindergarten through college study (Jackson, C. D. \& Leffingwell, 1999)? Burns (1998) in her book Math: Facing an American Phobia tackles an interesting subject and has found that two-thirds of American adults fear and loathe math. Whether it is $93 \%$ or two-thirds of Americans experiencing negative math experiences it is clear that there is a problem and we need to do something about it as educators. If math anxiety is such a problem, why isn't as much being done about it today?

Evidence of students' poor attitudes and high levels of anxiety toward math is abundant (Brown, Brown, \& Bibby, 2008). In the midst of a technological era, declining mathematics (math) scores in the USA on the Scholastic Aptitude Test (SAT) have been widely publicized, today many students are not performing well in math (Brown, Brown, \& Bibby, 2008). In their paper, they have found that many young people have perceived difficulty and lack of confidence as critical reasons for learners not continuing with math courses, and that perceived hate and boredom, and lack of real-life relevance, as other factors for not pursuing math fields and study (Brown, Brown, \& Bibby, 2008). Some reports have shown that American students rank last when compared with students from all other industrialized countries on 19 different assessments. The Third International Mathematics and Science Study (TIMSS) has shown a trend in U. S. students' math scores as they decline as students increase in age group from grade four to grade twelve compared to many other countries (Schmidt, 1998). What is happening to our students that so many of them lose interest in math and lack the confidence to do and take more math classes? Parker (1997) addresses this issue by interviewing math anxious individuals who share the causes for their math anxiety and what they did to help come up with solutions to their problem, which can serve as strategies described later in this paper.

To address the issue of math anxiety, classroom teachers need to team up with school counselors. Teachers need to be sensitive to students' needs, feelings, and experiences with mathematics. Brigman \& Campbell (2003) have found based on their research that when school counselors team up with classroom teachers they can have a profound effect on student achievement scores. A counselors' psychological expertise can serve as a real asset to classroom teachers and students who struggle with a fear of mathematics or poor past math instruction experiences. As educators, we need to remember that not all students are alike, yet all students deserve equal opportunities in the mathematics classroom (NCTM, 2000). A math teachers' job is not only to teach the subject area. One of National Council of Teachers of Mathematics goals for all learners was that as math teachers, we should help students become confident in their ability to do mathematics (NCTM 1989). NCTM $(1989,2000)$ believes that students should be exposed to numerous and varied interrelated experiences that encourage them to value math, to develop mathematical habits of the mind, they should understand the role of math in human affairs: they should be encouraged to guess, read, write, make conjectures and make errors so that they can gain confidence to solve complex problems. With this in mind, it is clear then that math teachers are not only instructional leaders, they are also counselors and confidence builders for their clients, their students.

\section{MATH ANXIETY DEFINED}

What is math anxiety? Well, to put it simply, it is anxiety when confronted with math, especially about one's own performance in solving math problems. It can range from slight nervousness to all-out panic. This anxiety makes it more difficult for students to focus in class, learn math, and solve math problems. Frequently students would rather give up than have to face their fears. This means that they never get better at math and can therefore never overcome their anxiety. If this anxiety is not addressed, the student may suffer from this anxiety for their entire life, even beyond their time in school. Math anxiety is a well-documented phenomenon that has affected our society for over sixty years, and not enough is being done to address it in our classrooms or in the way we teach math (Beilock \& Willingham, 2014; Boaler, 2008; Dowker, Sarkar, \& Looi, 2016; Geist, 2010). Negative attitudes toward mathematics and math anxiety are serious obstacles for students in all levels of schooling today (Geist, 2010). Beilock and Willingham (2014) state that "Because math anxiety is widespread and tied to poor math skills, we must understand what we can do to alleviate it" (p. 29).

Math anxiety is caused by a combination of external and internal factors; however, we cannot change internal factors within the student, so as teachers it makes more sense to focus on what we can control (Chernoff 
\& Stone, 2014). Studies show that math anxiety is caused primarily by the way the student learns math: the type of authority the teacher uses, an emphasis on right answers and fear of getting wrong answers, requirements that the student respond with an answer sooner than he or she might be ready, and exposure to the rest of the class and their potential condemnation of a student who responds poorly, in short the traditional way of teaching math (Chernoff \& Stone, 2014, Finlayson, 2014). Traditional teaching emphasizes:

- "Basic skills

- Strict adherence to fixed curriculum

- Textbooks and workbooks

- Instructor gives/students receive

- Instructor assumes directive, authoritative role

- Assessment via testing/correct answers

- Knowledge is inert

- Students work individually." (Finlayson, 2014)

Unfortunately, these methods can cause and increase math anxiety in the classroom (Finlayson, 2014).

Math anxiety can also be transmitted and learned from others, usually from parent to child or teacher to student, but occasionally student to student. If someone teaching math, whether to their own child or to a class, experiences math anxiety, they are more likely to rush through things in order to "get it over with." They wouldn't be sure of their methods, so they would focus more on the correct answer. Like the student with math anxiety, they are also likely to become exasperated and give up rather than continue helping the student. This teaches the student that math is something to be afraid of and that, if they are not good at it, their parent or teacher will become angry with them and potentially leave. They also learn in class that, if their peers see that they are bad at math, they will be ridiculed publicly. Embarrassment is a very big deal for children, especially in middle and high school.

Another problem for those who suffer from math anxiety is the nature of anxiety itself. According to Rubinstein et al (2015), anxious individuals tend to focus on negative stimuli more than positive stimuli, essentially making themselves more anxious. The same thing is true of individuals with math anxiety; the only difference is that for people with math anxiety, math is negative stimuli (Rubinstein et al, 2015). This suggests that math anxiety could be handled through therapies designed to lessen anxiety, such as cognitive behavioral therapy and exposure therapy (exposing a person little by little to the thing that they are afraid of) (Rubinstein et al, 2015). While this is not something that a teacher could do with a full class to manage, it is something that tutors could be trained to help with; naturally, a licensed therapist would be the best option, but not all therapists are trained to help students with math. A combination of the two fields would be optimal.

Math anxiety remains a perplexing, persistent, and only partially understood problem from which many people suffer, NCTM (1991, p. 6) says, "Classrooms should be mathematics communities that thrive on conjecturing, inventing, and problem solving, and that build mathematical confidence. Unfortunately, in this day and age many kids and adults do not feel confident in their ability to do math. Mathematics anxiety in students has become a concern for our high-tech world. Is it possible that only about 7 percent of Americans have positive experiences with mathematics from kindergarten through college study (Jackson, C. D. \& Leffingwell, 1999)? Burns (1998) in her book Math: Facing an American Phobia tackles an interesting subject and has found that two-thirds of American adults fear and loathe math. Whether it is $93 \%$ or two-thirds of Americans experiencing negative math experiences it is clear that there is a problem and we need to do something about it as educators. If math anxiety is such a problem, why isn't as much being done about it in our schools?

\section{PREVENTING MATH ANXIETY}

There are many things schools can do to help prevent math anxiety from occurring in students. It really is a complicated matter and may involve what happens to kids in and outside of the classroom. Teachers and parents can play a critical role in helping to develop positive dispositions toward math. It is important that teachers check for these positive attitudes and dispositions toward mathematics at an early age. Often students can develop such anxieties toward math very early on in their math classrooms due to poor teaching, drill and practice, strained testing situations, parental and teacher insecurities about their own math abilities, etc. The elementary and middle school years are critical to developing positive perceptions toward mathematics in children. The NCTM (2000, 1995, \& 1989) has made recommendations for preventing math anxiety with recommendations such as:

- accommodate different learning styles

- create a variety of testing environments

- design positive experiences in math classes

- remove the importance of ego from classroom practice

- emphasize that everyone makes mistakes in mathematics 
- make math relevant

- let students have some input into their own evaluations

- allow for different social approaches to learning mathematics

- emphasize the importance of original, quality thinking rather than rote manipulation of formulas; and emphasize the importance of original, quality thinking rather than rote manipulation of formulas

- characterize math as a human endeavor.

What it really comes down to is that teachers must employ best practices for teaching mathematics. Zemelman, Daniels, and Hyde (2012) based on a culmination of research have put together what is considered the "best practices" for teaching mathematics that all math teachers should incorporate into their instruction which include: (a) use of manipulatives (make learning math concrete); (b) use cooperative group work; (c) use discussion when teaching math; (d) make questioning and making conjectures a part of math; (e) use justification of thinking; (f) use writing in math for: thinking, feelings, and prob. Solving; $(\mathrm{g})$ use problem-solving approach to instruction; make content integration a part of instruction; (h) use of calculators, computers, and all technology; (i) being a facilitator of learning; and (j) assess learning as a part of instruction. Also, see Appendix A for a summary, which includes strategies/key ideas for preventing math anxiety.

\section{REDUCING/OVERCOMING MATH ANXIETY}

Reducing math anxiety is much different from preventing math anxiety. Teachers need to work with school counselors and to act as psychologist or counselors themselves to help lower or overcome such anxiety toward math in their students. It is critical that math teachers team up with school counselors to address reducing math anxiety in their students. Researchers in math anxiety propose systematic desensitization (Furner, 1996; Schneider \& Nevid, 1993; Hembree, 1990; Trent, 1985; Olson \& Gillingham, 1980) as an effective approach for helping people reduce their math anxiety. Systematic desensitization in the context of math anxiety may be defined as a gradual exposure to the mathematical concepts that are causing students to become distressed and teaching them how to cope with that fear. Each time they are exposed to the math they fear, they should improve in their techniques in coping with their anxious feelings. Being able to talk about their past history with math and releasing their anger, hatred and fear of the subject may be therapeutic. Through this counseling approach, students come to understand that their anxiety was a learned behavior, they were not born with this feeling, and they can be taught to overcome it by consistently implementing their self-monitoring strategies to become less anxious. Davidson and Levitov (1999) advocate the use of relaxation in conjunction with repeated positive messages and visualizations to reduce math anxiety.

How is math anxiety reduced? Teachers and counselors must help students understand how their math anxiety was created. According to Hackworth (1992), math teachers can use the the following activities to assist in reducing math anxiety: (a)discuss and write about math feelings; (b) become acquainted with good math instruction as well as study techniques; (c) quality studying; recognize type of information learning; (d) be an active learner and create problem solving techniques; (e) evaluate your own learning; (f) develop calming/positive ways to deal with fear of math and doing math: visualization, positive messages, relaxation techniques, and frustration breaks; and lastly (g) gradual repeated success in math builds confidence (See Appendix A). Tobias (1987) suggests that one way for students to reduce math anxiety is to recognize when panic starts, to identify the inactiveness in their analytic and retrieval systems, and to clear up the static without ceasing to work on the problem.

Ooten (2003) in her book, Managing the Mean Math Blues, outlines a four-step method for managing a persons' math anxiety. Ooten believes that a person who suffers from math anxiety needs to first lay the groundwork by coming to terms with their feelings and challenge their current beliefs and realize they are not alone; second, one must change their thoughts and negative thinking and use intervention strategies to improve ones thinking that they can be successful at math; third, one needs to know thyself, it is important that one knows his/her learning style/mode and that he/she apply approaches to doing math by successful people; and lastly fourth, once one has gained some confidence and strategies for doing mathematics they then must apply what they learned and actually do the math.

Campbell (2001), a school counselor, has developed a nine-session math confidence building group therapy workshop for students to help in overcoming and coping with their math anxiety. Campbell suggest that students who are math anxious should go through the following nine sessions with the math teacher and possibly a counselor:

Session 1: Drawing and goal setting in math

Session 2: Discussing past math feelings

Session 3: Learning to relax and cope with math fear and begin using "Math Feelings Journal"

Session 4: Using clay to vent anger from past math experiences and discuss ideal math classroom 
Session 5: Self-talk to develop positive thoughts about math learning

Session 6: Success imaging and creative visualizations, relaxation techniques to work toward math success

Session 7: Creating a math rap song about something the students like in math, continue to use the "Math Feelings Journal"

Session 8: Create a math fun mural to focus on positive aspects of math

Session 9: Creating confidence cards and sharing with group to discuss success with math

Campbell (2001) suggests that while conducting the nine-session therapeutic math confidence workshop the teacher and counselor need to be sensitive to students needs and feelings and that each student may progress at his/her own pace. Also, teachers and counselors need to incorporate booster sessions to maintain student confidence, she suggests that students should be encouraged to regularly use a "Math Feelings Journal" to manage anxious feelings when they crop up.

\section{BUILDING MATH CONFIDENCE}

Teachers and school counselors should work together to do many things in the classrooms to help build their students math confidence. One practical idea for teachers and students is for teachers to assess their students' dispositions toward math at the beginning of a school year by having them complete the following Mathitude Survey:

\section{Mathitude Survey}

1. When I hear the word math I ...........

2. My favorite thing in math is ............

3. My least favorite thing in math is ............

4. If I could ask for one thing in math it would be ...........

5. My favorite teacher for math is .......... because ...........

Journal writing in math classrooms has become an everyday event for many students. Students use journals to express their understanding of mathematical concepts. Journals can also be used to allow students to share feelings and experiences with math. Students are rarely asked how they feel about learning about different concepts and branches of mathematics. Teachers can get really get a better understanding and feel for any frustration student are feeling.

The following sample list of journal/discussion question math teachers may use with students to write about alone or to discuss and share together as a class or small group. Teachers must realize that for students to overcome or have their math anxiety reduced, they must first initiate this form of therapy by allowing students to express their true feeling about math and how they arrived at such a disposition toward math:

\section{Journal/Discussion Questions for Students in Groups}

1. Pretend that you have to describe mathematics to someone. List all the words or phrases you can think of that you could use.

2. Imagine yourself doing or using math either in or out of school. What does doing or using math feel like? Describe.

3. If math were a color, an animal, music, or food what would it be?

4. For me math is most like. Why?

5. Describe how you feel in a math class.

6. Are you the type to do well in math class? Why or why not?

The picture book, Math Curse (Scieszka \& Smith, 1995), addresses the issue of math anxiety. It is an excellent example of how educators have come to terms with the fact that not all people feel confident in their ability to do math. When Mrs. Fibonacci, an elementary school teacher, tells her class that they can think of almost everything as a math problem, one student becomes overwhelmed by the scope of math. This math anxiety becomes a real curse. However, the student eventually realizes that math is everywhere and there is no way of escaping it in daily life; therefore, the math anxious youngster recognizes math as a means of making one's life easier. This book may be used as a form of bibliotherapy to prompt discussion on the topic of math anxiety and allow other students to discuss their feelings on the topic to compare to the character in the book.

Hebert and Furner (1997) outline specific lessons and activities to help in reducing math anxiety with activities such as: role playing feelings and experiences with math classes/teachers; using a math journal for students to write in, so they may describe their feelings while doing math problems, writing letters to the main character of the book Math Curse; writing math anxiety poems and rap songs about math and/or their anxiety toward mathematics; writing a letter to and advice column about their math anxiety to get advice; designing anti-math anxiety bumper stickers to be plastered on their school lockers, providing students with a daily self-affirmation statement; providing students an opportunity to create original radio or television advertisements for a national anti-math anxiety 
campaign; and providing students an opportunity to select an artistic medium (i.e. magazine photo collage, penciled sketch) to illustrate their math anxiety to name a few. Hebert and Furner feel that teachers need to take the time in their math instruction to address such affective aspects of learning mathematics so that students can come to terms with their feelings toward mathematics.

In one study, Jackson \& Leffingwell (1999), cited that only 7 percent of the population in their study reported having positive experiences with mathematics from kindergarten through college. The study cited that there are many covert (veiled or implied) and overt (apparent and definite) behaviors exhibited by the math instructor in creating math anxiety in students. Things like difficulty of material, hostile instructor behavior, gender bias, perceptions of uncaring teacher, angry behavior, unrealistic expectations, embarrassing students in front of peers, communication and language barriers, quality of instruction, and evaluation methods of the teacher. Math instructors' behaviors and teaching methods can be hurtful and negative to students learning math. Math teachers need to take an active role in reducing performance anxiety in math. It is not uncommon that a student will say, "I like the class because of the teacher." It is often because the teacher knows how to present developmentally the subject matter, creates a learning environment conducive to learning with compassion, has high expectations for all students without regard to gender, race, or language barriers, and uses a variety of assessment methods and teaching styles to best reach all students. As we enter the new millennium, it is a teacher's obligation to see that all students are prepared for a high-tech society where one cannot afford to not feel confident in their ability to do math.

\section{TEACHERS AND COUNSELORS: HOW DO WE FIX MATH ANXIETY IN OUR SCHOOLS?}

To put it simply: better teaching. Finlayson (2014) suggests the constructivist style of teaching which emphasizes these main ideas:

- "Begin with the whole - expanding to parts

- Pursuit of student questions/interests

- Primary sources/manipulative materials

- Learning is interaction - building on what students already know

- Instructor interacts/negotiates with students

- Assessment via student works, observations, points of view, tests. Process is as important as product

- Knowledge is dynamic/change with experiences

- Students work in groups"

This style of teaching is very different from the traditional style which can cause and increase math anxiety. The constructivist style is much less intimidating and does not emphasize timed assessments or correct answers; instead, it focuses on the process of doing mathematics. Students are also likely to feel more engaged in class due to the more participatory style of teaching, making them want to work harder, instead of "getting it over with" heedless of how this affects their performance.

However, frequently the problems in the classroom that cause math anxiety are due to a teacher with math anxiety (Chernoff \& Stone, 2014). These teachers choose the easiest ways of teaching (rote memorization of formulas, practice using one method to get one right answer, timed tests, etc.) in order to minimize their own math anxiety, not realizing that they are passing their own anxiety onto their students (Chernoff \& Stone, 2014). Therefore, we must first remove math anxiety from teachers, so they may teach their students not to experience math anxiety. Math is not inherently frightening, but that is the message that is told to many children, even from their parents and teachers.

As mentioned previously, math anxiety is a form of anxiety and therefore treatable through the same types of therapy we use to treat general anxiety and phobias (Rubinstein et al, 2015). This may prove especially helpful for adults with math anxiety, especially teachers; by working to handle their own math anxiety, adults would be able to prevent transmission of their anxiety to their children or students (Chernoff \& Stone, 2014).

Ruff \& Boes (2014) claim in their research that teachers need to become and work with counselors to address math anxiety in their students. They found that so often math anxiety interventions seem to neglect the psychological and emotional aspects of math anxiety. Schools employ professional school counselors who are uniquely trained to assist students with a wide range of academic and personal/social stressors and could be effectively used to help students cope with math anxiety yet a further search of the literature related to school counseling and anxiety varied in suggestions to assist kindergarten to college students, but such interventions are not as common.

Ramirez, Gunderson, Levine, \& Beilock (2013) concluded in their research how critical it is for schools and teachers to address math anxiety when people are young. They found that high working memory (WM) individuals tend to rely on WM-intensive solution strategies, and these strategies are likely disrupted when WM capacity is co- 
opted by math anxiety. They argue that early identification and treatment of math anxieties is important because these early anxieties may escalate and eventually lead students with the highest potential to avoid math courses and math-related career choices. So, when teachers team up with school counselors they can better then identify such students early on.

Woodard (2004) found and recommends from her research that counselors can help math anxious students. She feels they can interview math-anxious students and make a math-anxiety problem known to teachers before a student begins a course. Furthermore, she feels that math anxiety scores and school and college placement scores could be compared to determine if a relationship exists between them. This could help educators determine if math anxiety has an effect on placement testing and if alternative means need to be used when placing students in developmental math courses. She emphasizes teachers work with counselors to identify and more effectively math anxious students so to address and prevent and/or reduce math anxiety in students.

\section{SUMMARY}

Teachers of mathematics need to take on the role of counselors to address the math anxious students they have in their classrooms. Based on research from above it is then recommended that math teachers team up with professional school counselors to employ the many suggestions and recommendations mentioned in this article in their classrooms/schools to help prevent and reduce math anxiety. Teachers may also want to work with school counselors as well as encourage their schools to have family math nights where parents come with children and together they can "do math" and see its importance and value in life. As a society, we must work together to extinguish the discomfort that our children are having toward mathematics in an age of STEM. It is important that all students feel confident in their ability to do mathematics in an age that relies so heavily on problem solving, technology, science, and mathematics. It really is a teachers' obligation to see that their students value and feel confident in their ability to do math, because ultimately a child's life: all decisions they will make and careers choices may be determined based on their disposition toward mathematics. As educators, we must make the difference in our children's attitudes toward math. Educators along with society as a whole need to strive toward creating mathematically literate and confident young people for the new millennium. It would be nice to hear more young people and adults when asked how they feel about math say, "Math is my favorite subject" or "I am great at math!" or "I can solve any word problem!" or "I am planning to go into a STEM field."

\section{REFERENCES}

Arem, C.A. (2003). Conquering math anxiety: A self-help workbook (2nd Ed.). Pacific Grove, CA: Brooks/Cole-Thomson Learning.

Beilock, S.L. and Willingham, D.T. (2014). Math anxiety: Can teachers help students reduce it? American Educator, 38(2), pp. 28-32.

Boaler, J. (2008). What's math got to do with it? Helping children learn to love their least favorite subject-and why it's important for America. New York, NY: Penguin Group (USA) Inc.

Brigman, G. and Campbell, C. (2003). Helping student improve academic achievement and school success behavior. Professional School Counseling, 7(2), pp. 91-98.

Brown, M., Brown, P. and Bibby, T. (2008). "I would rather die": reasons given by 16-year-olds for not continuing their study of mathematics. Research in Mathematics Education, 10(1), pp. 3-18. https://doi.org/10.1080/14794800801915814

Burns, M. (1998). Math: Facing an American Phobia. Sausalito, CA: Math Solutions Publications.

Campbell, C. (2001). Building math confidence. In G. Brigman and B. Earley-Goodman, (Eds.), Group Counseling for School Counselors, (2nd Ed.). Portland, ME: J. Weston Walch.

Chernoff, E. and Stone, M. (2014). An Examination of Math Anxiety Research. OAME/AOEM Gazette, pp. 2931.

Davidson, R. and Levitov, E. (1999). Overcoming math anxiety. Reading, MA: Addison Wesley.

Dowker, A., Sarkar, A. and Looi, C.Y. (2016). Mathematics Anxiety: What Have We Learned in 60 Years? Frontiers in Psychology, 7, p. 508. https://doi.org/10.3389/fpsyg.2016.00508

Finlayson, M. (2014). Addressing math anxiety in the classroom. Improving Schools, 17(1), pp. 99-115. https://doi.org/10.1177/1365480214521457

Furner, J.M. (1996). Mathematics teachers' beliefs about using the National Council of Teachers of Mathematics Standards and the relationship of these beliefs to students' anxiety toward mathematics. Unpublished doctoral dissertation. University of Alabama. 
Geist, E. (2010). The anti-anxiety curriculum: Combating math anxiety in the classroom, Journal of Instructional Psychology, 37(1), pp. 24-31.

Hackworth, R.D. (1992). Math anxiety reduction. Clearwater, FL: H \& H Publishing Company.

Hebert, T.P. and Furner, J.M. (1997). Helping high ability students overcome math anxiety through bibliotherapy. The Journal of Secondary Gifted Education, 4(8), pp. 164-178. https:// doi.org/10.1177/1932202X9700800403

Hembree, R. (1990). The nature, effects, and relief of mathematics anxiety. Journal for Research in Mathematics Education, 21, pp. 33-46. https:// doi.org/10.2307/749455

Jackson, C.D. and Leffingwell, R.J. (1999). The Role of Instructor in Creating Math Anxiety in Students from Kindergarten through College. Mathematics Teacher, 92(7), pp. 583-586.

National Council of Teachers of Mathematics. (1989). Curriculum and evaluation standards for school mathematics. Reston, VA.

National Council of Teachers of Mathematics. (1991). Professional standards for teaching mathematics. Reston, VA.

National Council of Teachers of Mathematics. (1995). Mathematics anxiety [Supplemental Brochure]. Reston, VA.

National Council of Teachers of Mathematics. (2000). Principles and Standards for School Mathematics. NCTM: Reston, VA.

Neunzert, H. (2000). Will Mathematics and the Mathematicians be able to contribute essentially in shaping the future? In 3ECM Conference Round Table Discussion on Shaping the 21st Century, Barcelona, Spain, July 11-14, 2000.

Oberlin, L. (1982). How to teach children to hate mathematics. School Science and Mathematics, 82, p. 261. https://doi.org/10.1111/j.1949-8594.1982.tb17187.x

Olson, A.T. and Gillingham, D.E. (1980). Systematic desensitization of mathematics anxiety among preservice elementary teachers. Alberta Journal of Educational Research, 26(2), pp. 120-127.

Ooten, C. (2003). Managing the mean math blues. Upper Saddle River, New Jersey: Pearson Education, Inc. of Prentice Hall.

Parker, S.L.B. (1997). Overcoming math anxiety: Formerly math-anxious adults share their solutions. Educational Specialist Thesis at the University of Georgia.

Ramirez, G., Gunderson, E.A., Levine, S.C. and Beilock, S.L. (2013). Math anxiety, working memory, and math achievement in early elementary school. Journal of Cognition and Development, 14(2), pp. 187-202. https://doi.org/10.1080/15248372.2012.664593

Reuters. (2007). Researchers: Math Anxiety Saps Working Memory Needed to Do Math. [online] Available at http://www.cnn.com/Interactive on February 20, 2007.

Rubinsten, O., Eidlin, H., Wohl, H. and Akibli, O. (2015). Attentional bias in math anxiety. Frontiers in Psychology, 6. https://doi.org/10.3389/fpsyg.2015.01539

Ruff, S.E. and Boes, S.R. (2014). The Sum of All Fears: The Effects of Math Anxiety on Math Achievement in Fifth Grade Students and the Implications for School Counselors. Georgia School Counselors Association Journal, 21(1), p. 1.

Schmidt, W.H. (1998). Changing mathematics in the U.S.: policy implications from the third international mathematics and science study. Presentation at the $76^{\text {th }}$ Annual meeting of the National Council of Teachers of Mathematics, Washington, D.C., April 3, 1998.

Schneider, W.J. and Nevid, J.S. (1993). Overcoming math anxiety: A comparison of stress inoculation training and systematic desensitization. Journal of College Student Development, 34(4), pp. 283-288.

Scieszka, J. and Smith, L. (1995). Math curse. New York: Viking.

Steen, L.A. (1999). Numeracy: The new literacy for a data-drenched society. Educational Leadership, October, 8-13.

Tobias, S. (1987). Succeed with math: Every student's guide to conquering math anxiety. New York: College Board Publications.

Tobias, S. (1993). Overcoming math anxiety revised and expanded. New York: Norton.

Trent, R.M. (1985). Hypnotherapeutic restructuring and systematic desensitization as treatment for mathematics anxiety. Paper presented at the annual convention of the Southwestern Psychological Association, Austin, Texas.

Woodard, T. (2004). The Effects of Math Anxiety on Post-Secondary Developmental Students as Related to Achievement, Gender, and Age. Inquiry, 9(1).

Zemelman, S., Daniels, H., and Hyde, A. (2012). Best practice: Bringing standards to life in America's classrooms (4th Ed.). Portsmouth, NH: Heinemann. 


\section{APPENDIX A}

Tips for Building Math Confidence in Young People

Mathematics teachers need to be counselors too

What NCTM says about Mathematics Anxiety and Dispositions Toward Mathematics

\section{Standard 10: Mathematical Disposition (NCTM 1989)}

As mathematics teachers, it is our job to assess students' mathematical disposition regarding:

- confidence in using math to solve problems, communicate ideas, and reason;

- flexibility in exploring mathematical idea and trying a variety of methods when solving;

- willingness to persevere in mathematical tasks;

- interests, curiosity, and inventiveness in doing math;

- ability to reflect and monitor their own thinking and performance while doing math;

- value and appreciate math for its real-life application, connections to other disciplines and cultures and as a tool and language.

\section{A Synthesis on How to Reduce Math Anxiety}

1. Psychological Techniques like anxiety management, desensitization, counseling, support groups, bibliotherapy, and classroom discussions.

2. Once a student feels less fearful about math he/she may build their confidence by taking more mathematics classes.

3. Most research shows that until a person with math anxiety has confronted this anxiety by some form of discussion/counseling no "best practices" in math will help to overcome this fear.

\section{A Synthesis on How to Prevent Math Anxiety}

1. Using "Best Practice" in mathematics such as: manipulatives, cooperative groups, discussion of math, questioning and making conjectures, justification of thinking, writing about math, problem-solving approach to instruction, content integration, technology, assessment as an integral part of instruction, etc.

2. Incorporating the NCTM Standards and your State Standards into curriculum and instruction.

3. Discussing feelings, attitudes, and appreciation for mathematics with students regularly. 